\title{
Tests of bond between concrete and steel bars - literature background and program of own research
}

\author{
Marcin Burdziński ${ }^{1}$, Maciej Niedostatkiewicz ${ }^{2}$, Patryk Ziółkowski ${ }^{3}$ \\ ${ }^{1}$ Doctoral School; Gdańsk University of Technology; Gabriela Narutowicza St. 11/12, \\ 80-233 Gdańsk, Poland; \\ marcin.burdzinski@pg.edu.pl iD 0000-0001-5965-4349 \\ ${ }^{2}$ Department of Concrete Structures; Faculty of Civil and Environmental Engineering; \\ Gdańsk University of Technology; Gabriela Narutowicza St. 11/12, 80-233 Gdańsk, Poland; \\ mniedost@pg.edu.pl iD 0000-0002-6451-6220 \\ ${ }^{3}$ Department of Concrete Structures; Faculty of Civil and Environmental Engineering; \\ Gdańsk University of Technology; Gabriela Narutowicza St. 11/12, 80-233 Gdańsk, Poland; \\ patziolk@pg.edu.pl iD 0000-0001-8809-6702
}

\begin{abstract}
This article deals with the issue of the bond between concrete and reinforcement. The bond is crucial for reinforced concrete elements because it is possible to transfer forces (stresses) from concrete to the reinforcement. Basic information related to the cooperation of concrete and rebars was recalled in the article. Selected issues concerning theoretical and numerical analysis as well as experiments of the bond phenomenon were presented. The article also proposes its own concept of experimental studies on the bond on two types of specimens: so-called short specimen and large specimen that will be subjected to pull-out tests. The described concept is ultimately to form the basis for creating a numerical model, enabling the simulation of bond in various reinforced concrete elements, calibrated based on the results of experimental studies.
\end{abstract} concrete

Keywords: reinforced concrete structures, bond, pull-out test, steel deformed bar,

\section{Introduction}

The basis of reinforced concrete structures work is the interaction between concrete and reinforcement. It is possible due to the bond, i.e. the cooperation of concrete and rebars in the transfer of forces (stresses) caused by loads. In this aspect, the most important are three phenomena related to bond:

- adhesion;

- friction;

- mechanical resistance. 
The first phenomenon that affects bond is adhesion. Adhesion is a chemical interaction and the forces (stresses) caused by it between concrete and bar are insignificant (according to researchers, the values of these stresses are usually from 0.4 to $0.8 \mathrm{MPa}$ [1]). The primary bond is involved in the area of adhesion - then in the considered normal cross-section to bar the strain in the reinforcing bar $\left(\varepsilon_{\mathrm{s}}\right)$ and surrounding tension concrete $\left(\varepsilon_{\mathrm{ct}}\right)$ are given by Eq. 1.:

$$
\varepsilon_{\mathrm{s}}(x)=\varepsilon_{\mathrm{ct}}(x)
$$

If the bond stress exceeds the value of the stress associated with adhesion, then the mechanism of cooperation between concrete and reinforcement is referred to as the secondary bond. This means that in the considered cross-section, the strains of the steel bar $\left(\varepsilon_{\mathrm{s}}\right)$ are greater than the strains in the tensile concrete surrounding it $\left(\varepsilon_{\mathrm{ct}}\right)$, and the difference between these strains is called slip $(S)$, as shown in Eq. 2:

$$
\frac{d s}{d x}=\varepsilon_{\mathrm{s}}(x)-\varepsilon_{\mathrm{ct}}(x)
$$

If a crack appears (which is primarily associated with exceeding the concrete tensile strength), then the stress at the concrete-bar interface increases rapidly, which causes local loss of bond and slip of reinforcement relative to the concrete. Due to the nature of reinforced concrete structures work, the secondary bond is the main object of analysis.

The second phenomenon that affects the bond is friction. Friction was important for plain bars, which now have been replaced by deformed bars. In the initial phase of the bond mechanism, friction does not play a significant role in the deformed bar. It acquires significance in the situation when there is advanced destruction of the bond, i.e. when the longitudinal cracks formed to the axis of the bar allow slipping at the interface of concrete between the bar ribs and the concrete surrounding the bar. In Fig. 3 the described situation is shown by a horizontal line. Concrete shrinkage plays a positive role in friction, which is usually not desirable in concrete structures due to the appearance of additional tensile stresses. It causes the rebar to be clamped by the concrete.

The last phenomenon affecting the bond is mechanical resistance. It is crucial in the case of deformed bars in terms of cooperation at the concrete-bar interface. In the plain bars used in the past, the only mechanical resistance was the hooks at their ends. Deformed bars interlock in concrete thanks to the ribs, which enable achieving much higher values of bond stress. According to [2], plain bars show up to 1.5 times less bond strength compared to deformed bars. The presence of ribs also causes the formation of internal cracks which at a sufficiently high level of effort are visible on the outer edge of the element (Fig. 1).

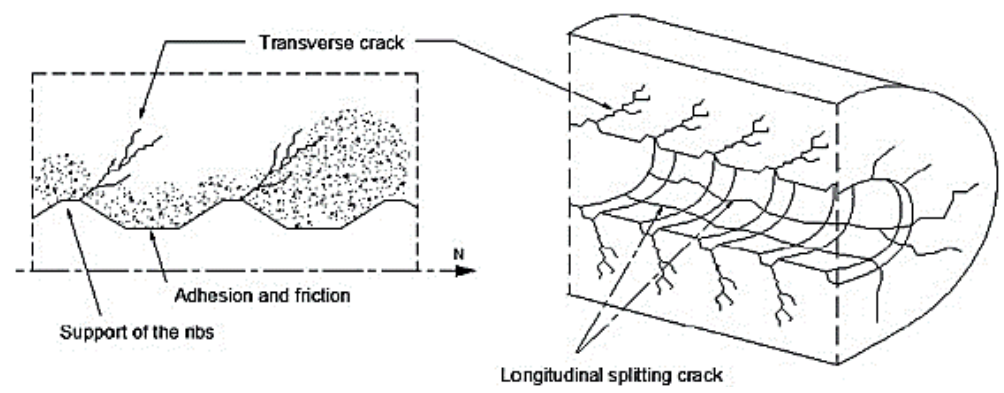

Fig. 1. The action of adhesion, friction, mechanical resistance, and cracking caused by the cooperation of concrete and deformed bar. Source: [3] 
The problem of bond has been the subject for many years of both theoretical analyses, experimental studies conducted on various specimens as well as numerical analysis. The article will present issues related to the theoretical description of the bond phenomenon between concrete and steel deformed bars, selected methods, and elements for studying this phenomenon will be characterized. Besides, the own program of bond experimental studies will be presented.

\section{Bond mechanism between concrete and bar}

\subsection{Theoretical analysis}

The theoretical analysis of cooperation between concrete and reinforcement consists in a mathematical description of phenomena occurring in a reinforced concrete element during its work, which results in the deformability of the element. To make such a description, it is necessary to formulate functions that take into account given quantities in any cross-section on the considered length of the element (e.g. between two adjacent cracks). This section was prepared based on [1]. Important values are:

- strains in tensile concrete in extreme fibres $\left(\varepsilon_{\mathrm{ct}}\right)$;

- strains in compressed concrete in extreme fibres $\left(\varepsilon_{\mathrm{c}}\right)$;

- tensile rebar strains $\left(\varepsilon_{\mathrm{s}}\right)$;

- bar slip relative to concrete $(s)$;

- bond stress value $\left(\tau_{\mathrm{b}}\right)$.

There are some assumptions and relationships between the above functions that make up the differential equations.

The first relationship is the strains compatibility condition, which was already presented in Eq. 2. It was assumed that the difference in strains of the rebar and the surrounding concrete is called slip. The interpretation of this condition depends on the analysed part of the specimen. For the specimen face, the slip is the difference in total strains in the rebar and the concrete. For the central part of the specimen, multiplying by two integrated Eq. 2 within the length of the bond violation section can be treated as the crack opening width.

The second relationship is the equilibrium condition of the forces in the cross-section of the bar. On Fig. 2 the equilibrium of the infinitesimal bar segment is presented.

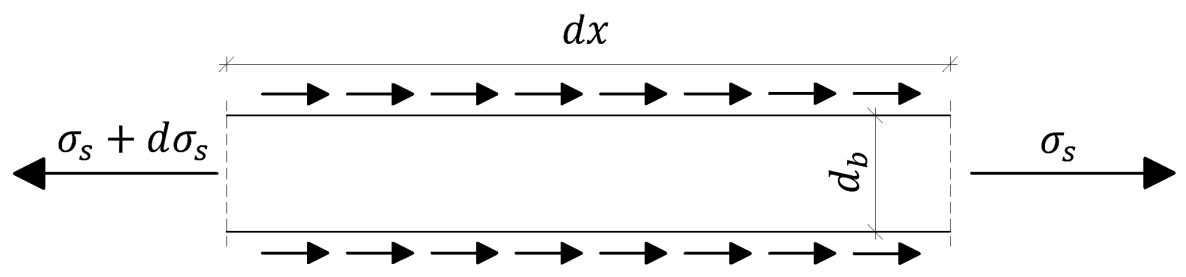

Fig. 2. Equilibrium of the infinitesimal bar segment. Source: own study

Equilibrium condition of the infinitesimal bar segment from Fig. 2 is described by Eq. 3:

$$
\left(\sigma_{\mathrm{s}}+d \sigma_{\mathrm{s}}\right) \cdot \frac{\pi d_{\mathrm{b}}^{2}}{4}-\sigma_{\mathrm{s}} \cdot \frac{\pi d_{\mathrm{b}}^{2}}{4}=-\pi d_{\mathrm{b}} d x \tau_{\mathrm{b}}
$$


Finally, the equilibrium condition of the forces in cross-section of the bar has the form Eq. 4:

$$
\frac{d \sigma_{\mathrm{s}}}{d x}=\frac{-4 \tau_{\mathrm{b}}}{d_{\mathrm{b}}}
$$

The next relationships are the conditions of forces in the specimen cross-section. The form of these conditions is determined by the stress state of the specimen. Besides, these conditions must consider the bar slip relative to the concrete. Attention should be paid to the principle of flat cross-sections, which, when slip is considered, works only for concrete in the compression zone and reinforcing bars (for eccentric tension or bending).

The last relationship is a bond function. These functions describe the relationship between bond stress and the parameters which the analysed element has. These parameters take into account selected factors affecting the bond. Most often they are related to concrete strength and bar geometry. Bond functions play a key role in the transition from experimental studies to theoretical analysis, which is why they should be as simple as possible and accurately reflect the bond stress distribution relative to the adopted variables. The results of tests carried out in the past indicate that the obtained bond functions accurately represent only a specific situation, which means that it can be assigned to only one specimen. So far, no function has been obtained that comprehensively describes the entire specimen (i.e. the face and centre of the specimen).

Another issue is the "quality" of the bond function, and another the possibility of its use in the theoretical analysis of the bond. "Quality" is understood as the level of accuracy reflecting the distribution of bond stress in the specimen. It sometimes happens that the function is characterized by very high "quality", but its use in theoretical analysis is not possible due to the differential equation that does not have a closed solution or the adopted boundary conditions relate to a too narrow range of analysis or specific case. The search for the bond function was and is the subject of interest of many researchers who over the years have presented various approaches to this issue. In general, bond functions can be divided into three groups:

Group no. 1- bond functions based on the assumption that the bond depends in any cross-section only on the slip value of the reinforcing bar $(s)$ relative to the concrete surrounding the bar. The functions of the form are determined based on classic pull-out tests. This test consists in pulling out the bar from a concrete block in which the embedded length is from two to five of bar diameter. The most popular bond function representing this group is shown by Eq. 5:

$$
\tau_{\mathrm{b}}(s)=\tau_{\max } \cdot\left(\frac{s}{s_{\max }}\right)^{\alpha}
$$

where:

$\tau_{\mathrm{b}}(s)$ - bond stress value corresponding to bar slip $(s)$;

$\tau_{\max }-$ maximum bond stress value (bond strength);

$S-$ slip of a pulling out bar;

$S_{\max }$ - slip corresponding to the value $\tau_{\max }$;

$\alpha$-experimental parameter.

This bond function was first formulated in the 1980s by Bertero, Eligehausen, and Popov. This function is found in CEB-FIP Model 1990 [5], as well as in fib Model Code 2010 [6] as part of the function describing the bond model (in the range $0 \leq s \leq s_{1}$ ) (Fig. 3). 


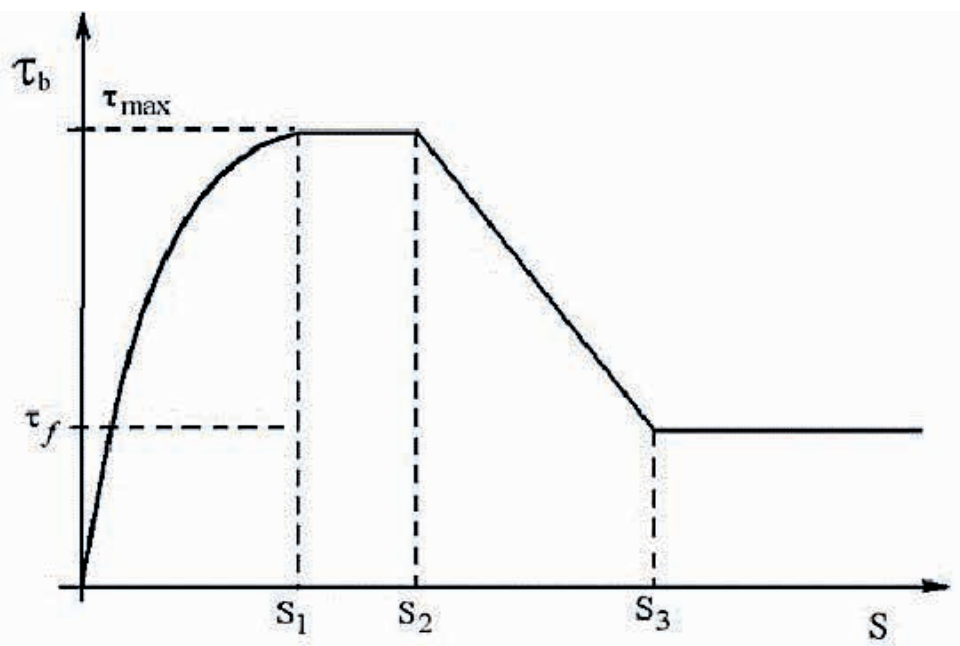

Fig. 3. Bond-slip curve according to CEB-FIP Model 1990 and fib Model Code 2010. Source: [5]

Group no. 1 also includes bond functions described by polynomials [7] or simplified linear or bilinear functions.

The undoubted advantage of the bond function from the group no. 1 is the simplicity of the tests that are carried out to determine it, as well as the ease of using them in the models used in FEM analysis. Unfortunately, there are serious and well-founded reservations about these functions. Firstly, Eq. 5 shows that a given slip $(s)$ always corresponds to the same value of bond stress $\left(\tau_{\mathrm{b}}\right)$, and this is not true. Secondly, the same formula also shows that the greater the slip value, the greater the bond stress value. In the cross-section in which the crack was formed, the bar has the greatest slip relative to the concrete, and the bond stress at this point is, in fact, zero, so the above observation is also not true.

The last problem related to the group no. 1 of the bond function is mathematical because in the deformation analysis these functions lead to differential equations that have no closedform solutions.

Group no. 2 - bond functions depend on the location of the cross-section over the considered element length $(x)$ and the slip value $(s)$. These functions are determined based on tests carried out on large specimens, i.e. those in which the embedded length is much greater than five diameters of the anchored bar. The progenitor of the bond function from the group no. 2 is Arthur H. Nilson, who in the early 1970s presented his idea of describing the bond stress distribution. An example of the function from the group no. 2 is given by Eq. 6 [8]:

$$
\tau_{\mathrm{b}}(x, s)=\left(k_{0}-k_{1} x\right) \cdot s^{\alpha}
$$

where:

$\tau_{\mathrm{b}}(x, s)$ - bond stress value corresponding to the cross-sectional location $(x)$ and the bar slip $(s)$;

$k_{0}, k_{1}, \alpha$ - function parameters;

$x$ - bar cross-section location;

$s-$ bar slip. 
Bond functions included in this group are characterized by a high level of reflecting the bond stress distribution. Unfortunately, the disadvantage is the lack of universalism because these functions apply to specific cases of tested elements that are not suitable for the analysis of other specimens. Unambiguous interpretation of the results of the experiments is also troublesome. Besides, these functions create problems through a complex mathematical form, which causes a lot of trouble in the theoretical analysis (no closed form). An attempt to get out of the situation is to use simplifications that inevitably reduce the "quality" of the function. An additional complication is a method of obtaining the bar slip value. In practice they are calculated, which raises doubts related to their correctness in relation to the actual values of slip.

A separate problem is the elements used in the tests to determine the bond function of the group no. 2. Unfortunately, the problems are related to the basic issues, which are measurements of strains in the reinforcing bar and concrete. Doubts often arise from the correctness of the measurements taken, their impact on the disturbance of element work, and, consequently, the usefulness of the obtained results. Problems and inconveniences related to that specimen are described in more detail later in the article.

Group no. 3 - bond functions dependent only on the cross-section position $(x)$ between the cracks (independent of slip $(s)$ ). The bond functions of this group can be called compromise. Their form allows avoiding problems with obtaining differential equations in a closed-form. These functions depend only on the cross-section position, which is undoubtedly a simplification relative to the function of the group no. 2. It necessarily results in a decrease in the "quality" of these functions. The level of reduction in "quality" depends on the case of the bond function. An example of the function from the group no. 3 is given by Eq. 7 [9]:

$$
\tau_{\mathrm{b}}(x)=\tau_{\mathrm{b}, \max } \cdot\left[1-\left(1-4 \cdot \frac{x}{l_{\mathrm{b}}}\right)^{2}\right]
$$

where:

$\tau_{\mathrm{b}}(x)$ - value of the bond stress corresponding to the cross-section position $(x)$;

$\tau_{\mathrm{b}, \max }-$ maximum bond stress value (bond strength);

$x$ - bar cross-section location;

$l_{\mathrm{b}}$ - length of the primary bond loss.

As already mentioned, the functions of this group depend on the location of the analysed cross-section. This means that the issue related to conducting the tests is identical to the bond function of the group no. 2, which in turn means the same problems as before. Besides, there is the issue of determining the length of the primary bond loss $\left(l_{b}\right)$, which is most often taken as the distance between two adjacent cracks. The problem is significant because this length occurs in each bond function from the third group (see Eq. 7).

The study of the bond phenomenon and the conclusions drawn from them enable better analysis of the deformation of reinforced concrete elements. Due to the large number of factors that affect the bond, as well as the problems associated with conducting tests, and taking into account the complicated theoretical analysis of the concrete and rebar cooperation, one should approach the bond tests with great caution. According to [10], a general theoretical concept should be created, then on this base, the specimens on which the experiments will be conducted. It is also important to determine the research methodology. This approach can eliminate potential errors, but also increase the chance of better observation of the bond phenomenon. This is a major remark because the mentioned order usually was the reverse. 


\subsection{Experimental studies}

Experimental studies regarding the cooperation between concrete and a deformed bar are carried out on three scales [11]:

- rib scale (Fig. 4a);

- bar scale (Fig. 4b);

- member scale (Fig. 4c).

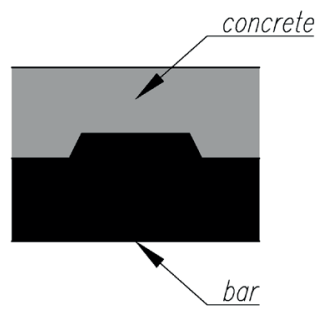

a)

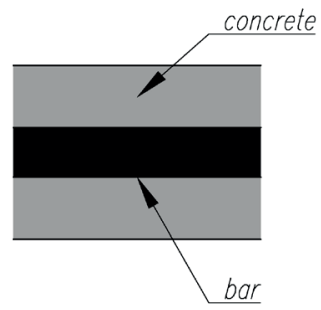

b)

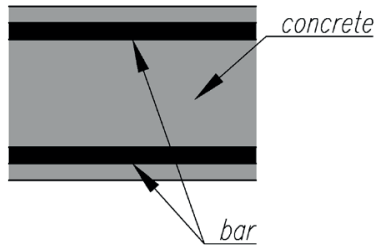

c)

Fig. 4. Scales of the bond observation: a) rib scale, b) bar scale, c) member scale. Source: own study

The analysis of bond mechanisms carried out at the rib scale is the most detailed. It relates to contact phenomena occurring at the bar ribs-concrete interface. A classic test at this scale of observation is the pull-out test (Fig. 5), from which the information on the mechanisms of destruction of the bond is obtained. The embedded length, i.e. the section where the interaction between the bar and concrete takes place, is from two to five diameters of the pulling out $\operatorname{bar}\left(2-5 d_{b}\right)$. They are the so-called "short specimens", in which it is assumed that over such a short section bond stress has a constant value. The Eq. 8 can be used to determine the value of said bond stress during the pull-out test:

$$
\tau_{\mathrm{b}}=\frac{F}{\pi \cdot d_{\mathrm{b}} \cdot l_{\mathrm{b}}}
$$

where:

$\tau_{\mathrm{b}}$ - bond stress;

$F$ - force with which the bar is pulling out;

$d_{\mathrm{b}}$ - bar diameter;

$l_{\mathrm{b}}$ - embedded length.

displacement

Fig. 5. Specimen using in classic pull-out test. Source: own study 
The pull-out test consists in pulling out a reinforcing bar from a concrete block (usually cubic [12], but also cuboidal [13] or cylindrical [14]), during which the force with which the bar is pulling out is measured, and the bar end slip corresponding to this force (free end or free and fixed end). The main result of the pull-out tests is the bond-slip curve. Based on this test, bond functions are created and modified that only depend on the slip value (see section 2.1 - group no. 1 of the bond function). Recommendations regarding the pull-out test were released e.g. by RILEM [15] and were also included in the standard [16].

The pull-out test is extremely popular because it is easy to perform and is inexpensive, and at the same time it considers many factors related to concrete and rebar. That is why there are a lot of publications devoted to this study, in which the influence of selected factors on the bond is checked, e.g. new generation concretes [17], non-metallic bars [18], steel bar corrosion [19], extreme temperatures [18], [20] and others.

Results from a pull-out test on a short specimen should not be used for specimens at a different scale of bond observation. This is because the concrete in this test is compressed and the bar is tensile, which is in no way related to the work of the tension zone of the reinforced concrete elements. In addition, the short specimen prevents the formation of internal cracks, which results in excessive values of the bond strength $\left(\tau_{b, \max }\right)$, compared to real reinforced concrete elements. As mentioned, assumptions about the bond function obtained from this test and, as a consequence, their form exclude the possibility of their use in the bond analysis at other scales of bond observation, due to existing contradictions and inconveniences (see section 2.1 - group no. 1 of the bond function).

When conducting analysis at the bar scale, the matter is much more complicated. Carrying out experiments at this scale makes it possible to learn and refine the mechanisms of transfer forces (stresses). The bond stress distribution along the length of the specimen is of key importance. This is important from the point of view of engineering practice because the results of the conducted analysis can affect the calculation and control of the crack opening width and the development length. A typical test for this type of bond observation scale is the pull-out test on a large specimen (i.e. one where the embedded length is much greater than five diameters of the anchored bar) or double pull-out test, i.e. pulling out the bar on both sides of the specimen (Fig. 6). The advantage of this test is the correct representation of the tension zone of the reinforced concrete element.
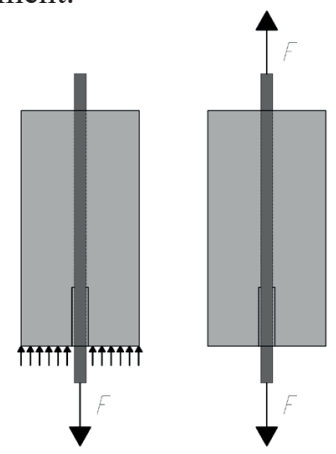

Fig. 6. Large specimen using in pull-out test (left), specimen using in double pull-out test (right). Source: own study

Analysis at the bar scale is very troublesome. The problem appears at the very beginning when selecting the research element. It must best reflect the conditions in the real structural element 
while allowing the observation of phenomena occurring in the specimen. Another big issue is the method of measuring strains both in the reinforcing bar and in concrete. One way to measure strains in a bar is to cut it, place strain gauges inside it and reweld the bar [21]. There are serious doubts about the usefulness of the results obtained in this way. Firstly, cutting and rewelding change the steel structure of the bar. Secondly, making the specimen is difficult and expensive. Thirdly, there is usually a large dispersion of results, which leads to the reflection about whichabout values are consistent with reality. On their basis, the bond stress is determined by Eq. 9:

$$
\tau_{\mathrm{b}, \mathrm{i}}=\frac{-d_{\mathrm{b}}}{4} \cdot \frac{\varepsilon_{\mathrm{s}, \mathrm{i}+1}-\varepsilon_{\mathrm{s}, \mathrm{i}-1}}{x_{\mathrm{i}+1}-x_{\mathrm{i}-1}} \cdot E_{\mathrm{s}}
$$

where:

$\tau_{\mathrm{b}, \mathrm{i}}-$ bond stress in cross-section ;

$d_{\mathrm{b}}$ - bar diameter;

$\varepsilon_{\mathrm{s}, \mathrm{i}+1}-$ strain in the reinforcing bar in cross-section $\mathrm{i}+1$;

$\varepsilon_{\mathrm{s}, \mathrm{i}-1}-$ strain in the reinforcing bar in cross-section $\mathrm{i}-1$;

$\mathrm{x}_{\mathrm{i}+1}-$ position of the cross-section $\mathrm{x}+1$ relative to the specimen face;

$\mathrm{x}_{\mathrm{i}-1}$ - position of the cross-section $\mathrm{x}-1$ relative to the specimen face;

$E_{\mathrm{s}}-$ Young's modulus of reinforcing steel.

The matter of measuring strains in concrete looks even worse. From the bond analysis, it should be known concrete strains near the bar. It is worth noting that the strains in concrete at the cross-section height are different. Also, the concrete strains along the element length are not uniform due to its cooperation with the reinforcement.

When analysing the bond at the bar scale, attention should be paid to the stress state of the tested specimen. The results of testing a specimen subjected to e.g. axial tension, in the bending element analysis cannot be accepted, because the stress state affects the bond mechanisms [22] and on the way cracks form [23].

Due to the long-embedded length, two types of bond functions are determined and modified based on the bar scale. The first type of bond function depends on the slip and position of the bar cross-section (see section 2.1 - group no. 2 of the bond function), while the second type of bond function depends only on the position of the bar cross-section (see section 2.1 group no. 3 of the bond function).

The last scale of bond observation is the member scale. Tests on this level are carried out on construction elements, on a laboratory, semi-industrial or industrial scale (real construction elements). Thanks to this, the results of experiments on this observation scale of the bond phenomenon can be easily applied to engineering practice related primarily to the process of designing reinforced concrete structures (e.g. determination of the development length). Due to the widespread use, the most common research element on this scale is a simply supported reinforced concrete beam.

Because of the analysed specimen size, the bond is represented by the tension stiffening phenomenon. This phenomenon considers the effect of concrete work in the tension zone of a reinforced concrete element after cracking. During the design process, it is assumed that only reinforcement works in the tension zone. In fact, concrete also cooperates with reinforcement between cracks, which has a positive effect on the stiffness of the entire element.

In summary, the study of the bond phenomenon between concrete and reinforcing bars is carried out at three scales. Their selection determines the detail of the analysis, the method 
of conducting investigations, and the obtained results. Unfortunately, the transition between these scales is not easy, which is a significant obstacle to the development of bond analysis. The most important for engineering practice are the two discussed scales of bond observation, i.e. bar scale and member scale, as the results obtained from them have the greatest impact on the issues of designing concrete structures. In the literature, one can find remarkable suggestions for the transition between these scales [24], as well as examples of their use [25].

\subsection{Numerical analysis}

The third way to analyse the bond between concrete and reinforcement is to use computer engineering analysis. Models used in computer mechanics for analysis of the bond have a broad spectrum - from simple linear finite elements imitating the interaction of concrete and reinforcement [26], through a simplified approach to bond modelling [27], ending with advanced, detailed, three-dimensional models using the fracture mechanics and taking into account formation of internal cracks in the vicinity of the bar [28].

Numerical analysis can consider many factors related to the bond and successfully reflect the specimens state subjected to tests. However, these analyses complement and extend the theoretical analysis and experimental studies. This is because the material models used in numerical calculations are calibrated based on experiments. There are therefore two doubts. Firstly, all problems and inconveniences associated with specimens and tests also automatically concern the computational model. Secondly, the computational model (better or worse) reflect specific specimen, while for another it may not show satisfactory convergence, which is characteristic of experimental studies, because their results are often burdened with the size effect, which consists in counting the influence of the element proportion on the characteristics of its work. That is why it is so important that the selected numerical models are based on algorithms concerning the lack or minimization of the size effect [29], [30].

\section{Own program of testing the bond in concrete}

The presented review on theoretical analysis, experimental studies and numerical analysis of the bond phenomenon was the basis for developing the authors' own program for testing cooperation between the concrete and deformed bar. The proposed solutions constitute a compromise, bearing in mind the problems, doubts and controversies that arise from the analyses described, e.g. the problem of measuring strains in a reinforcing bar. The main goal of this concept is the validation of the numerical model using the results of experimental studies of the bond phenomenon, which will allow for satisfactorily accurate simulation of the cooperation concrete and steel ribbed reinforcing bars in selected reinforced concrete elements. The authors would like to point out that this concept is at the initial stage of its creation. Its first stage is experimental studies of the bond using the pull-out test method.

\subsection{Research elements - so-called short specimen}

For the short specimen, a $16 \mathrm{~mm}$ diameter steel deformed bar (B500SP EPSTAL) anchored in a concrete cube (C30/37) with a side length equal to $160 \mathrm{~mm}$ (ten times the bar diameter) will be used for the pull-out test. The embedded length will be $80 \mathrm{~mm}$ (five times the bar diameter). It can, therefore, be assumed that the bond stress distribution over this section is constant, and the strains change along the bar axis are linear. On the 
remaining $80 \mathrm{~mm}$ the bar will be surrounded by a $20 \mathrm{~mm}$ inner tube to ensure that the bar and concrete do not work together. The tube will not have contact with the pulling out bar, so it will not disturb measurements made during the test. The described specimens were mainly developed based on RILEM recommendations [15].

Tests will be carried out on four different specimens differing in position of the pulling out bar - i.e. in the middle of the specimen height (Fig. 7a), shifted down by $20 \mathrm{~mm}$ (Fig. 7b), shifted down by $40 \mathrm{~mm}$ (Fig. 7c) shifted down by $47 \mathrm{~mm}$ (Fig. 7d) relative to the centre of the specimen. The cover of the bars, measured from the bottom of the specimen, will be $72,52,32,25 \mathrm{~mm}$, respectively. The formwork for the described specimens is shown in Fig. 8.

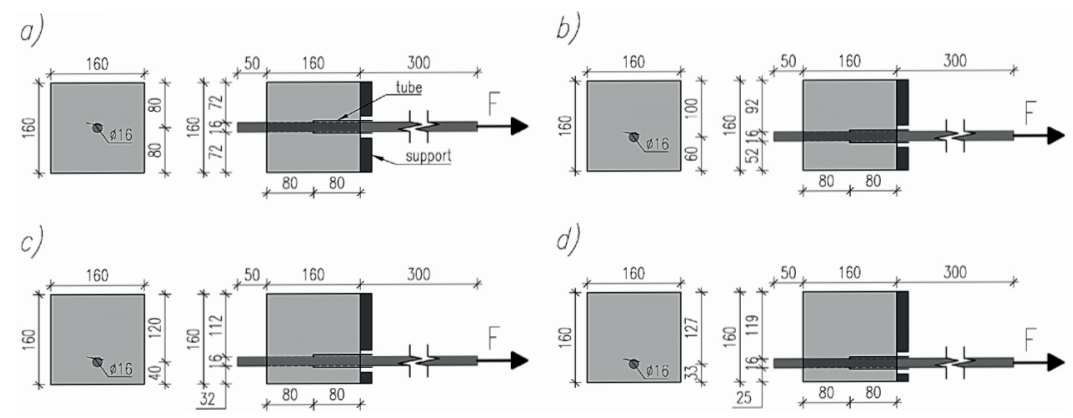

Fig. 7. Details of short specimens (description in the text). Source: own study

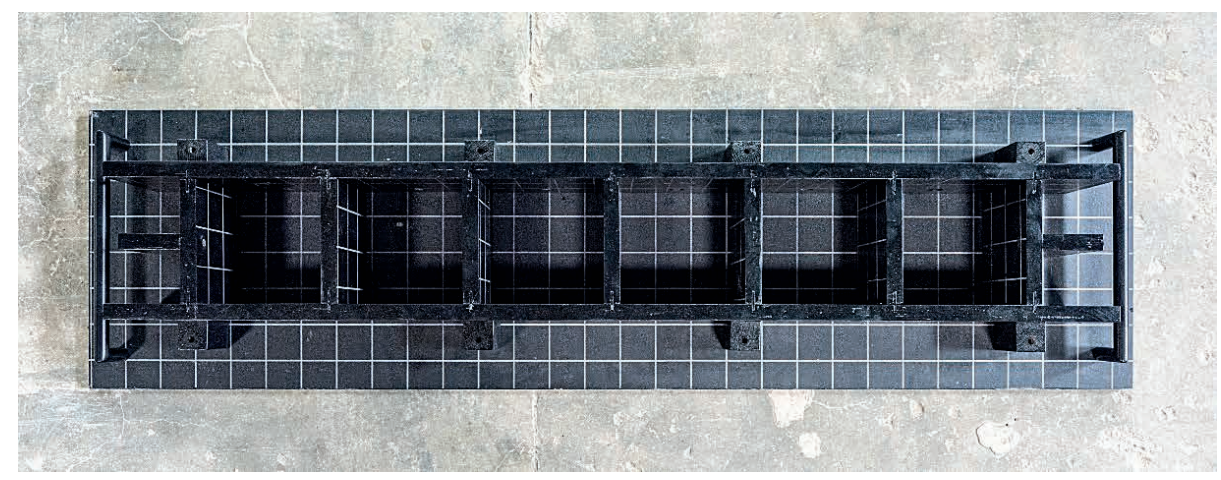

Fig. 8. Short specimens formwork. Source: own study

\subsection{Research elements - so-called large specimen}

For the large specimen, the pull-out test will be used a $16 \mathrm{~mm}$ steel deformed bar (B500SP EPSTAL) anchored along the axis of the concrete cuboid (C30/37) with a $160 \mathrm{~mm}$ square section and $800 \mathrm{~mm}$ length (five times the short specimen length). The bar cover will be equal to $72 \mathrm{~mm}$. The embedded length will be $720 \mathrm{~mm}$ (45 times the diameter of the pulling out bar). In this situation, it is not possible to assume a constant bond stress distribution on this section of cooperation between the concrete and the bar. A tube is to be placed on the $80 \mathrm{~mm}$ section insulating the bar from the side of the loaded end of the bar, analogously to the short specimen, which will allow comparison of the bond stress distribution in the face part of the large specimen and short specimen. 


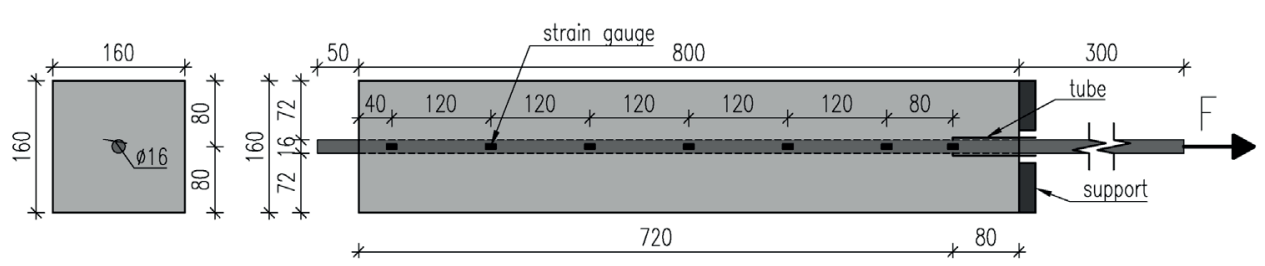

Fig. 9. Details of large specimen (description in the text). Source: own study

Strain gauges will be mounted on the surface of the reinforcing bar. Their spacing and other details of the large specimen are shown in Fig. 9. The relatively large spacing of strain gauges is dictated by their impact on the cooperation of concrete and the reinforcing bar. A smaller spacing would interfere too much with the analysed bond phenomenon. Fig. 10 shows the formwork for large specimens.
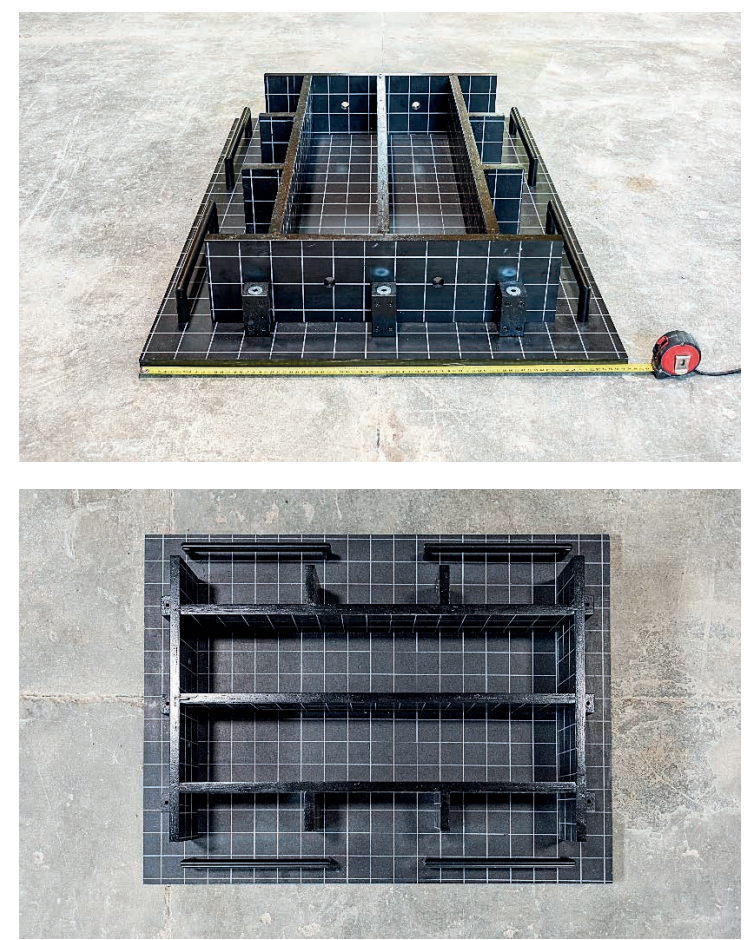

Fig. 10. Large specimens formwork. Source: own study

\subsection{Test stand}

Fig. 11a shows a schematic view of the test stand for pull-out tests. It is a metal cage in which the test specimen is located. The reinforcing bar anchored in the concrete block is clamped by the lower grips of the testing machine. In fact, the concrete block is pulling out from the reinforcing bar. The displacement of the unloaded bar end is measured relative to the upper surface of the concrete block. The described cage is adapted for testing both short and large specimens. Fig. 11b shows the cage that the authors of the article use during research in the laboratory. 
a)

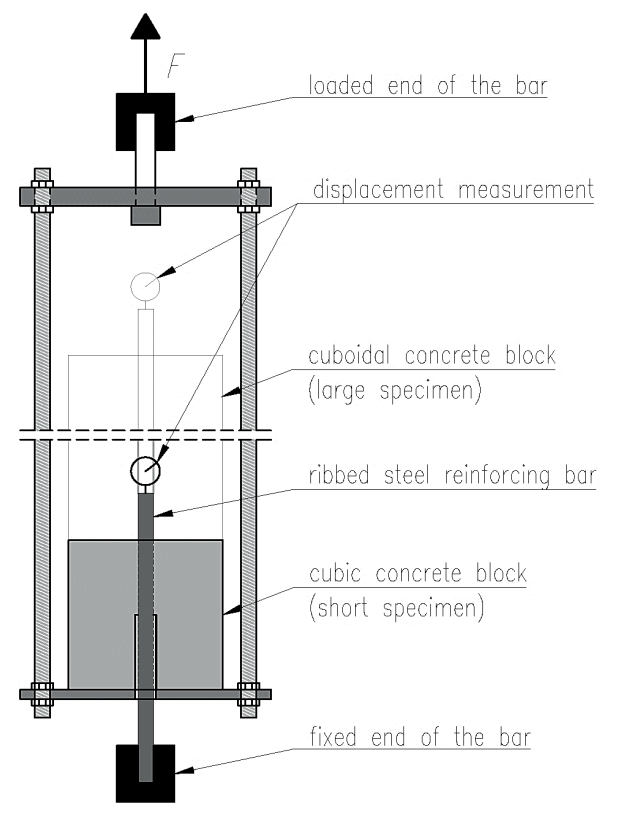

b)

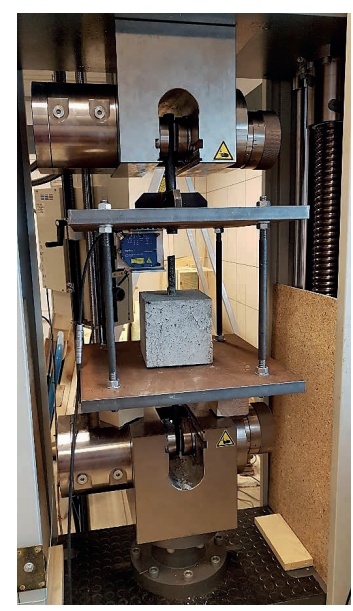

Fig. 11. a) Schematic view of the test stand, b) The actual view of the test stand. Source: own study

\subsection{Expected test results}

Pull-out tests on short specimens are typical bond tests at the rib scale (see section 2.2). The result of this type of testing will primarily be the bond-slip curve $(\tau-s)$. Thanks to the different locations of the bar in the concrete block (different bar cover thickness), it will be possible to observe the effect of the position of the pulling out bar on the said curve and on the manner of bond destruction in the specimen (splitting or pull-out failure) [31].

Pull-out tests on large specimens are tests at the bar scale (see section 2.2). This level of bond observation requires strain measurements in the reinforcing bar. It has been assumed that strain gauges will be located on the bar surface. Their spacing and other details of the large specimen are shown in Fig. 9. The results of the pull-out test for a large specimen are the determination of the bond stress distribution along the bar axis based on the measured strains, in accordance with Eq. 9. In addition, it is possible to observe the crack pattern of the concrete specimen and possibly compare the values and bond stress distribution in the face of a large specimen and in the short specimen.

\section{Summary}

The analysis of the bond phenomenon in reinforced concrete structures is complicated. It results, among others, from the difficulties of conducting experimental studies or advanced computer simulations, as well as often mathematical descriptions are difficult. In addition, the bond is affected by many factors that decide about the cooperation of concrete and reinforcing bars. 
This article proposes the authors' own experimental studies program for concrete and reinforcement interaction. Creating our own research program will allow for a better understanding of the effect of the bond in reinforced concrete structures and may help to systematize the conduct of experiments. It should be noted that creating such a concept is a process. In the future, this concept will be developed by carrying out tests on various types of specimens and their modifications.

The cooperation of concrete and rebars in reinforced concrete elements is tested using three types of analysis: theoretical, experimental, and numerical. These types of analyses are not independent of each other. This observation is particularly important when creating own concept of experimental studies because its main goal is to collect the necessary results and information for validation of the numerical model, which will allow for satisfactorily accurate simulation and consideration of the bond phenomenon in selected reinforced concrete elements.

\section{References}

[1] Pędziwiatr J., Podstawowe zagadnienia przyczepności stali i betonów w elementach żelbetowych. Oficyna Wydawnicza Politechniki Wrocławskiej, Wrocław 2007.

[2] Grabiec K., Projektowanie przekrojów w konstrukcjach z betonu. Arkady, Warszawa 1982.

[3] Sulaiman M.F. et al., "A Review on Bond and Anchorage of Confined High-strength Concrete", Structures, 2017 (11), pp. 97-109. https://doi.org/10.1016/j.istruc.2017.04.004

[4] EN 1992-1-1, Eurocode 2: Design of Concrete Structures - Part 1-1: General Rules and Rules for Buildings, 2004.

[5] CEB-FIP Model Code, First Draft, Committee Euro-International du Beton, Bulletin d'information, no. 195, 196, Mars 1990.

[6] fib Model Code for Concrete Structures 2010.

[7] Mirza S., Houde J., "Study of Bond Stress-Slip Relationships in Reinforced Concrete", ACI Journal, vol. 76, no. 1, Symposium Paper, January 1979, pp. 19-46.

[8] Kankam Ch., "Relationship of Bond Stress, Steel Stress, and Slip in Reinforced Concrete", Journal of Structural Engineering, 1997, vol. 123, no. 1, pp. 79-85.

[9] Jiang D., Shah S., Andonian A., "Study of the Transfer of Tensile Forces by Bond", Journal of the American Concrete Institute, May-Jun 1984, 81(3), pp. 251-259.

[10] Pędziwiatr J., "The new model for cracking analysis of tension reinforced concrete members based on the bond-slip relationships", Arch. Viv. Eng., 1996, vol. 42, no. 1, pp. 47-64.

[11] Cox J., Herrmann L., "Development of a plasticity bond model for steel reinforcement", Mech. Cohesive-Frict. Mater., 1998, vol. 3, pp. 155-180. https://doi.org/10.1002/(SICI)1099-1484(199 804)3:2<155::AID-CFM45>3.0.CO;2-S

[12] Zhao J., Cai G., Yang J., "Bond-slip behavior and embedment length of reinforcement in high volume fly ash concrete", Materials and Structures, 2016, vol. 49, pp. 2065-2082. https://doi. org/10.1617/s11527-015-0634-2

[13] Li X., Zhang J., Liu J., Cao W., "Bond Behavior of Spiral Ribbed Ultra-high Strength Steel Rebar Embedded in Plain and Steel Fiber Reinforced High-Strength Concrete", KSCE Journal of Civil Engineering, 2019, vol. 23, no. 10, pp. 4417-4430. https://doi.org/10.1007/s12205-019-2449-0

[14] Deshpande A.A., Kumar D., Ranade R., "Temperature effects on the bond behavior between deformed steel reinforcing bars and hybrid fiber-reinforced strain-hardening cementitious composite", Construction and Building Materials, 2020, vol. 233. https://doi.org/10.1016/j.conbuildmat.2019.117337

[15] RILEM/CEB/FIP, Recommendations on reinforcement steel for reinforced concrete, Revised edition of RC6 Bond test for reinforcement steel: (2). Pull-out test, CEB News, May 1983, no. 73. 
[16] PN-EN 10080 - Stal do zbrojenia betonu - Spajalna stal zbrojeniowa - Postanowienia ogólne, 2007.

[17] Ganesan N., Indira P.V., Sabeena M.V., "Bond stress slip response of bars embedded in hybrid fibre reinforced high performance concrete", Construction and Building Materials, 2014, vol. 50, pp. 108-115. https://doi.org/10.1016/j.conbuildmat.2013.09.032

[18] Solyom S., Di Benedetti M., Guadagnini M., Balázs G.L., "Effect of temperature on the bond behaviour of GFRP bars in concrete", Composites Part B: Engineering, 2020, vol. 183. https:// doi.org/10.1016/j.compositesb.2019.107602

[19] Chen J., Zhang B., Yang O., Long S., Xu F., Yang C., "Impact of anchorage length on bond performance between corroded reinforcing steel bars and concrete", Materials Reports, 2019, vol. 33, pp. 3744-3751. https://doi.org/10.11896/cldb.18110090

[20] Bednarek Z., Ogrodnik P., Kamocka-Bronisz R., Bronisz S., „Badanie wpływu temperatur występujących w czasie pożaru oraz szokowego chłodzenia na przyczepność stali B500SP i BST500S do betonu", Safety \& Fire Technique / Bezpieczeństwo i Technika Pożarnicza, 2013, vol. 29, no. 1, pp. 67-73.

[21] Liu K., Yan J., Zou C., Meng X., "Bond behavior between deformed steel bars and recycled aggregate concrete after freeze-thaw cycles", Construction and Building Materials, 2020, vol. 232. https://doi.org/10.1016/j.conbuildmat.2019.117236

[22] Base G., "Bond and Control of Cracking in Reinforced Concrete", in International Conference Bond in Concrete, Applied Science Publishers, London 1982, pp. 446-447.

[23] Drobiec Ł., Jasiński R., Piekarczyk A., Diagnostyka konstrukcji żelbetowych. T.1, Metodologia, badania polowe, badania laboratoryjne betonu i stali. Wydawnictwo Naukowe PWN, Warszawa 2010.

[24] Lackner R., Mang H.A., "Scale Transition in Steel-Concrete Interaction. I: Model”, Journal of Engineering Mechanics, 2003, vol. 129, no. 4, pp. 393-402. https://doi.org/10.1061/ (ASCE)0733-9399(2003)129:4(393)

[25] Lackner R., Mang H.A., "Scale Transition in Steel-Concrete Interaction. II: Applications", Journal of Engineering Mechanics, 2003, vol. 129, no. 4, pp. 403-413. https://doi.org/10.1061/ (ASCE)0733-9399(2003)129:4(403)

[26] Ngo D., Scordelis A., "Finite element analysis of reinforced concrete beams", ACI Journal, 1967, vol. 64 , no. 3 , pp. $152-163$.

[27] Hameed R., Sellier A., Turatsinze A., Duprat F., "Simplified approach to model steel rebar-concrete interface in reinforced concrete", KSCE Journal of Civil Engineering, 2017, vol. 21, no. 4, pp.1291-1298. https://doi.org/10.1007/s12205-016-1397-1

[28] Ueda T., Sato Y., Tadokoro T., "Prediction of Tension Behavior of Reinforced Concrete Members with Bond Model", in Bond in Concrete - from research to standards. Budapest, 2002, pp. 293-299.

[29] Suchorzewski J., Korol E., Tejchman J., Mroz Z., "Experimental study of shear strength and failure mechanisms in RC beams scaled along height or length", Engineering Structures, 2018, vol. 157, pp. 203-223. https://doi.org/10.1016/j.engstruct.2017.12.003

[30] Suchorzewski J., Marzec I., Korol E., Tejchman J., "Investigations on strength and fracture in RC beams scaled along height or length, Meschke G., Pichler B., Rots J.G.”, in Conference on Computational Modelling of Concrete and Concrete Structures (EURO-C). Bad Hofgasein 2018, pp. 651-661. https://doi.org/10.1201/9781315182964

[31] Den Uijl J.A., Bigaj, A.J., “A bond model for ribbed bars based on concrete confinement”, Heron, 1996, vol. 41, no. 3, pp. 201-226. 
